\title{
Review of Antiplatelet Therapy for the Management of Acute Coronary Syndromes
}

Dear editor,

Currently, cardiovascular diseases are the most common cause of morbidity and mortality in worldwide. Acute coronary syndromes (ACS) form a significant percentage of this disease spectrum. ACS encompasses non-ST-segment elevation myocardial infarction (NSTEMI), STEMI, and unstable angina. The basic pathophysiology of ACS comprises plaque rupture with subsequent activation of the coagulation cascade, resulting in thrombus formation, and partial or complete occlusion of the coronary artery. There have been significant improvements in the treatment options and prognosis in ACS patients in the last couple of decades. Antiplatelets play a key role in the management of these patients, and this review focuses on the acute and longterm antiplatelet therapy for ACS patients.

The current standard antiplatelet treatment for ACS patients consists of acetylsalicylic acid (aspirin) and a P2Y12 receptor antagonist (clopidogrel, prasugrel, or ticagrelor). ${ }^{[1,2]}$ ACS patients are initially given a loading dose of both aspirin $(300 \mathrm{mg}$ ) and a P2Y12 receptor antagonist (clopidogrel $=600 \mathrm{mg}$ or prasugrel $=60 \mathrm{mg}$ or ticagrelor $=180 \mathrm{mg}$ ). Dual antiplatelet therapy is continued for $12 \mathrm{months}$ usually, followed by monotherapy with aspirin or one of the P2Y12 receptor antagonists.

\section{Aspirin}

Aspirin is one of the oldest and very effective treatment strategies for ACS patients. Aspirin use in MI was studied in the International Study of Infarct Survival-2 trial, ${ }^{[3]}$ when aspirin and streptokinase was compared against placebo. There was a dramatic improvement in the prognosis of these patients with reductions in mortality, non-fatal MI, and stroke with aspirin. Aspirin also had an additive benefit effect on top of streptokinase in these patients. Because of these remarkable results aspirin very quickly became a standard treatment strategy in ACS patients.

\section{Clopidogrel}

The evidence base for clopidogrel comes mainly from CURE ${ }^{[4]}$ and COMMIT ${ }^{[5]}$ trials. In the CURE study, which was a study in patients with non-ST elevation ACS, clopidogrel on top of aspirin improved outcomes of death from cardiovascular cause, nonfatal MI, stroke or refractory ischemia. However, this did come at a cost of increased risk of major bleeding (3.7\% vs. 2.7\%, hazard ratio [HR] $=1.38 ; P=0.001)$. The COMMIT trial recruited 45,852 patients with acute MI and studied the effect of clopidogrel in addition to aspirin as compared with placebo and for a period of up to 4 weeks. Clopidogrel reduced both primary end points (composite of death from cardiovascular cause, nonfatal MI, or cerebrovascular accident (CVA); death from any cause) without increasing bleeding.

\section{Prasugrel}

Prasugrel was studied in the TRITON-thrombolysis in MI (TIMI) $38^{[6]}$ and TRILOGY-ACS ${ }^{[7]}$ studies. In the TRITON study, 13,608 patients with ACS and who were planned to undergo percutaneous coronary intervention were randomized in a double-blind fashion to $10 \mathrm{mg}$ of prasugrel or $75 \mathrm{mg}$ of clopidogrel for 12 months. Prasugrel significantly reduced the composite primary end point of death from cardiovascular causes, non-fatal MI, or CVA as compared to clopidogrel $(9.9 \%$ vs. $12.1 \%, \mathrm{HR}=0.81 ; P<0.001)$. The primary end point was mainly driven by reduction in rates of non-fatal $\mathrm{MI}$ in the prasugrel cohort. There was a significant increase in non-coronary artery bypass grafting (CABG) and CABG-related TIMI major bleeding in the prasugrel cohort. In TRILOGY ACS study, prasugrel was tested against clopidogrel in medically managed ACS patients. Prasugrel failed to show any significant benefit over clopidogrel in terms of composite primary end point of death from cardiovascular cause, non-fatal MI, or CVA. 


\title{
Ticagrelor
}

Platelet inhibition and patient outcomes trial ${ }^{[8]}$ investigated ticagrelor against clopidogrel in the prevention of cardiovascular events in 18,624 patients with ACS. At 12 months ticagrelor significantly reduced the composite primary end point of death from cardiovascular causes, MI or CVA (9.8 vs.11.7\%: HR = 0.84, $P<0.001)$. Ticagrelor did not increase overall major bleeding as compared to clopidogrel (11.6\% vs. 11.2\%, $P=0.43)$, but there was a statistically significant increase in non-CABG-related major bleeding with ticagrelor (4.5\% vs. $3.8 \%, P=0.03)$.

In summary, antiplatelet treatment strategies have revolutionized the management of ACS patients. They have resulted in significant improvement in the prognosis of these patients with better rates of mortality, MI and stroke. However, they do come with a risk of higher bleeding in these patients. Bleeding risk has to be considered especially in the elderly, patients with significant comorbidities and postoperative patients before instituting dual antiplatelet therapy. Dual antiplatelet therapy is necessary usually only for 1 year after ACS and also after revascularization with angioplasty. After 1 year of dual antiplatelet treatment patients should be shifted to monotherapy with aspirin or one of the P2Y12 antagonists unless there is ongoing increased risk of further cardiovascular events. This is particularly important, as there is a definite increased risk of bleeding with dual therapy as compared to monotherapy. Also need to mention here that all ACS patients will need monotherapy life-long.

\section{Ganesh Nallur Shivu}

Consultant, Department of Cardiovascular Sciences, Sparsh Hospitals, Bengaluru, Karnataka, India

\author{
Address for correspondence: \\ Dr. Ganesh Nallur Shivu, \\ Sparsh Hospitals, Bengaluru, \\ Karnataka, India. \\ E-mail: drgani23@gmail.com
}

\section{References}

1. Hamm CW, Bassand JP, Agewall S, Bax J, Boersma E, Bueno H, et al. ESC Guidelines for the management of acute coronary syndromes in patients presenting without persistent ST-segment elevation: The Task Force for the management of acute coronary syndromes (ACS) in patients presenting without persistent ST-segment elevation of the European Society of Cardiology (ESC). Eur Heart J 2011;32:2999-3054.

2. The Task Force on the management of ST-segment elevation acute myocardial infarction of the European Society of Cardiology (ESC), Steg PG, James SK, Atar D, Badano LP, Blömstrom-Lundqvist C, et al. ESC guidelines for the management of acute myocardial infarction in patients presenting with ST-segment elevation. Eur Heart J 2012;33:2569-619.

3. Randomised trial of intravenous streptokinase, oral aspirin, both, or neither among 17,187 cases of suspected acute myocardial infarction: ISIS-2. ISIS-2 (Second International Study of Infarct Survival) Collaborative Group. Lancet 1988;2:349-60.

4. Yusuf S, Zhao F, Mehta SR, Chrolavicius S, Tognoni G, Fox KK; Clopidogrel in Unstable Angina to Prevent Recurrent Events Trial Investigators. Effects of clopidogrel in addition to aspirin in patients with acute coronary syndromes without ST-segment elevation. N Engl J Med 2001;345:494-502.

5. Chen ZM, Jiang LX, Chen YP, Xie JX, Pan HC, Peto R, et al. Addition of clopidogrel to aspirin in 45,852 patients with acute myocardial infarction: Randomised placebo-controlled trial. Lancet 2005;366:1607-21.

6. Wiviott SD, Braunwald E, McCabe CH, Montalescot G, Ruzyllo W, Gottlieb S, et al. Prasugrel versus clopidogrel in patients with acute coronary syndromes. N Engl J Med 2007;357:2001-15.

7. Roe MT, Armstrong PW, Fox KA, White HD, Prabhakaran D, Goodman SG, et al. Prasugrel versus clopidogrel for acute coronary syndromes without revascularization. N Engl J Med 2012;367:1297-309.

8. Wallentin L, Becker RC, Budaj A, Cannon CP, Emanuelsson H, Held C, et al. Ticagrelor versus clopidogrel in patients with acute coronary syndromes. N Engl J Med 2009;361:1045-57.

\section{Financial Support: None; Conflict of Interest: None}

How to cite this article: Shivu GN. Review of antiplatelet therapy for the management of acute coronary syndromes. J Med Sci Health 2016;2(3):34-35.

Date of submission: 25-06-2016

Date of peer review: 04-10-2016

Date of acceptance: 05-10-2016

Date of publishing: 20-10-2016 